\title{
Diversified firms: existence and behaviors
}

\author{
Birger Wernerfelt \\ MIT Sloan School of Management, MIT, Cambridge, MA, USA \\ Corresponding author. Email: bwerner@mit.edu
}

(Received 8 May 2021; revised 9 August 2021; accepted 10 August 2021; first published online 3 September 2021)

\begin{abstract}
We propose a micro-founded theory of diversified firms. The theory suggests that diversified firms exist because they allow better deployment of factors that, because of sub-additive contracting costs, are hard to trade in fractions. Firms diversify into industries in which these factors are more productive than any alternatives available in the factor market. Like markets, diversified firms allow specialization by enabling factors to be used on a larger scale. The individual businesses making up a diversified firm exhibit specific similarities in behavior.
\end{abstract}

Keywords: Capabilities; contracting costs; diversified firms

\section{Introduction}

Diversified firms dominate the economy ${ }^{1}$ and yet almost all economic reasoning is based on models without them. We here develop a new, micro-founded explanation for the existence of these firms, as well as a characterization of their behavior. Specifically, the theory portrays diversified firms as mechanisms that leverage factors that cannot easily be traded in fractions - a category that includes many factors commonly cited as sources of competitive advantage, including brand names, IP, teams of employees, and relationships with trading partners. These factors need not be inherently indivisible, but the contracting costs make them effectively so. The businesses making up diversified firms are neighbors in two senses: they need the services of the factor in question and when shared, this factor is still more productive than any substitute that can be bought in the factor market. Beyond explaining why these firms exist and what constitutes them, the analysis yields two additional results. First, it suggests that optimal management results in specific similarities in the behavior of their constituent businesses. Second, it adds to Adam Smith's insight that markets enable specialization by showing that diversified firms do so as well.

The theoretical argument relies on two forces, sub-additive contracting costs and advantages of specialization, to define, justify, and characterize diversified firms. Sub-additivity plays two roles in the argument, and we will discuss them in turn.

Consider first the problem of contracting between a user of a productive factor and the owner of that factor. They could write many contracts, say 100, each of which specify that the user can utilize the factor in a particular way in return for a payment. Alternatively, they could write a single contract specifying that the user can choose to utilize the factor in any of the 100 ways in return for an average per-use payment. The sub-additivity assumption states that the latter contract, which covers 100 different uses, costs less than 100 single-use contracts. For human factors, this means that an employment contract, which gives the boss the right to tell the employee which of many possible tasks to

\footnotetext{
${ }^{1}$ The combined worldwide sales of the US Fortune 500, almost all of which operate in multiple businesses, is roughly equal to $3 / 4$ of the US GDP.

( $)$ The Author(s), 2021. Published by Cambridge University Press on behalf of Millennium Economics Ltd. This is an Open Access article, distributed under the terms of the Creative Commons Attribution licence (http://creativecommons.org/licenses/by/4.0/), which permits unrestricted re-use, distribution, and reproduction in any medium, provided the original work is properly cited.
} 
perform, can be cheaper than a sequence of negotiations over single tasks. For non-human factors, it means that an ownership contract, which gives the owner the right to decide what to do with the factor, can be cheaper than a sequence of rental contracts. From this perspective, employment contracts and ownership contracts are identical; they both confer broad rights of control to the user of the factor and allow costless adaptation. The sub-additivity assumption ensures that they can be cheaper than large sets of narrow contracts conferring the same rights.

We use these contracts to define the scope of firms. Specifically, from this perspective, the scope of a firm consists of the human and physical factors tied to it by employment and ownership contracts. The scope of a diversified firm is not given by the output markets in which it is active, but by the productive factors over which it has contractual control.

This definition unifies elements from two different streams in the theory of the firm. Most literature has defined firms based on either employment (Barnard, 1938; Simon, 1951) or asset ownership (Grossman and Hart, 1986), but not both. Our definition combines those and speaks to Hodgson's (2019) suggestion that the recent lack of progress in the theory of the firm can be attributed to economists' failure to agree on a definition. $^{2}$

The theory is less synthetic when it comes to the transactions costs motivating the existence of firms. Some literature (Grossman and Hart, 1986) focus on ex ante investment distortions and others look at the costs of ex post adaptations (Bajari and Tadelis, 2001; Coase, 1937; Hart and Moore, 2008; Matouschek, 2004). Our paper falls squarely in the latter category in which Wernerfelt (1997) was the first to look at the case in which the adaptation costs are sub-additive.

The second role of sub-additivity depends on advantages of specialization and is more direct. Suppose that a firm controls a specialized factor but cannot put all its capacity to the use in which it is specialized (as is, e.g. the case for many intangible factors). In such cases, sub-additivity tends to make it inefficient to trade or rent out the excess capacity, at least compared to use in a pair of businesses which are 'similar' in the sense that some advantages of specialization transfers between them. So it might be efficient for the firm to diversify by entering such a business.

Let us now walk through three examples to highlight the intuition behind the model and the results. Each of the examples will highlight a factor that can be specialized along two dimensions and the idea is that it will be most productive if it is doubly specialized and deployed exclusively in the corresponding narrow zone. (In the model, we label the two dimensions as service- and business-specialization, but the examples will illustrate a wider set of cases.)

\subsubsection{Example 1: advertising agencies ${ }^{3}$}

Advertising agencies design, produce, and book appropriate ads in several media (print, video, and digital). In the typical situation, each of these nine tasks is performed by a team of specialized experts, and individual team members can in turn do better if they can specialize in an even narrower sub-task (selecting colors for print ads, editing video clips, booking social media ads, etc.). However, there are also advantages of specialization along the nature of the products or services advertised: a team is more efficient if it works on similar brands (two items for teenagers versus one item for teenagers and a financial product, two 'green' brands versus one green brand and one luxury brand, etc.).

Suppose now that a one-brand luxury company needs a team to design a digital ad. The company would, ceteris paribus, prefer to use a team that is 'doubly specialized' - in the design of digital ads and in messaging for luxury brands. If the company cannot utilize an efficiently sized team on a full-time basis, it would have to settle for a team that is specialized in only one of the two dimensions: It could work with an external agency and share the digital design team's time with other customers, or it could hire its own team and have them do design for all media (not just digital). However, if the company diversified, by acquiring or building a second luxury brand, it might be able to use a doubly specialized team on a full-time basis.

\footnotetext{
${ }^{2}$ For related discussions see Langlois (1995), Carter and Hodgson (2006), Gindis (2016), and Deakin et al. (2021).

${ }^{3}$ This example is taken from Wernerfelt et al. (2021).
} 


\subsubsection{Example 2: rental property maintenance ${ }^{4}$}

A small landlord typically maintains a rental property in one of two ways: Either by employing a jack-of-all-trades superintendent or by hiring independent specialists, such as plumbers, electricians, etc. However, by acquiring other, similar, buildings, our landlord might be able to employ, on a fulltime basis, a set of doubly specialized craftsmen - each of whom know both a trade and the type of buildings they work on.

\subsubsection{Example 3: brand names}

Brand names are specialized in two ways. First, they signal an attribute that is desirable for some products, but not for others ('McDonald's' is a better fit for a bacon cheeseburger than for shampoo). Second, they only help sales to segments of consumers who know them (a brand name normally used on teen products would not be ideal for a Medicare supplement). Brand names have a lot of excess capacity - the same name can be used on many different products. ${ }^{5}$ It is, however, very hard to write a contract that allows two different firms to share a brand name. So while umbrella branding is common, it is almost always in the form of diversification. To get extra leverage out of its brand name, a firm should diversify in a direction that allows it to take advantage of both dimensions of specialization: the signaled attribute should be important for the new product and the target segment should already know and like the brand.

\subsection{Preview of the model}

A factor's productivity when performing a particular service for a particular business depends on the narrowness of its specialization and the match between it and the (service, business) pair in question. To describe this, we will introduce the concept of factor capital. Just like human capital can be service specific and/or firm specific, other factors can be specialized along the same two dimensions. ${ }^{6} \mathrm{We}$ assume that a factor can be specialized or un-specialized in both domains. If it is specialized in a particular service (business), it is more productive if it is providing that service (working for that business), but then also less productive if it has to perform a different service (work for a different business). So a factor is most productive if it is specialized in both service and business domains and can perform the same service for the same business in every period.

However, if the individual businesses are scale constrained and do not need the same services in every period, such double specialization can be inefficient. It is often better to specialize in one domain only. For example, a factor that is specialized in the service domain but not in the business domain can follow the demand for that service from business to business. Conversely, a factor that is specialized in the business domain but not in the service domain can provide a series of different services for that business.

Factors can, however, approximate double specialization by taking advantage of business 'neighborhoods'. This concept captures the observation that some pairs of businesses are more 'similar' than others. There are two aspects of similarity: Business specialized factors and services needed. ${ }^{7}$ First, some pairs of businesses use similar factor capital, such that specialized business skills transfer at least partially, making the factor more productive than an unspecialized alternative. ${ }^{8}$ Second, some pairs of businesses tend to need some of the same services, such that a factor will be able to leverage narrow service-specialization in one of the two firms in almost every period.

To see the role of neighborhoods in efficient production, consider a factor whose capital is doubly specialized in an individual business and an individual service. This factor may be able to perform the chosen service for the businesses in the neighborhood on a full-time basis. When these businesses are

\footnotetext{
${ }^{4}$ An expanded version of this example is used in Wernerfelt (2015).

${ }^{5}$ Montgomery and Wernerfelt (1992) report that $83 \%$ of products evaluated in Consumer Reports are umbrella branded.

${ }^{6}$ We will use the term business specialization to cover specialization in a trait the business shares with very few, ideally no, other firms.

${ }^{7}$ As shown in the Corollaries 1 and 3, it turns out that we need both properties to make our argument.

${ }^{8}$ This links the model to the strategy literature because it means that the factor confers a 'competitive advantage'.
} 
independently operated, they could be seen as a local market. However, if the neighborhood businesses are operated by a single entrepreneur and this entrepreneur owns (or employs) the factor, they would constitute a diversified (or multi-business) firm.

To explain this, we posit that bilateral contracting is burdened by contracting costs, for example, from bargaining. The crucial assumption is that these costs are sub-additive in the number of possible services covered by the contract. For example, if the contract gives the entrepreneur the right to ask for any one of $S$ services, then the cost of contracting on it are less than $S$ times the cost of contracting on a single service.

The sub-additivity is key because it makes it possible to compare alternative contracts: The parties may agree on a sequence of contracts for individual services on an as-needed basis, or they may eliminate all later contracting by once-and-for-all agreeing on a price for which the factor would provide any service in any business the entrepreneur asks for. Under this blanket contract, the factor provides any of several services on demand with no further contracting, thus making adaptation costless. It is an ownership or employment contract depending on whether the factor is human or not and it is more efficient if more frequent adaptation is necessary. (As pointed out by Grossman and Hart (1986), ownership confers the right to make residual use decisions by fiat. That is, just like employment, it allows adaptation without negotiation.) So we will define a 'firm' by the factors tied to it through ownership and employment contracts.

Based on this we can use the model to explain the existence of diversified firms. Think of a business neighborhood and factor that is doubly specialized to one of the businesses and an individual service. No single business will need the service in question every day, but on many days, at least one business in the neighborhood will. For simplicity, assume exactly one. The services of the factor could be traded through a sequence of daily market contracts between its owner and the business which needs the service in question on that day. But if all the businesses are managed by the same entrepreneur, a once-and-for-all employment or ownership contract eliminates the need for any further contracting.

\subsection{Literature}

Despite their massive importance in modern economies, the mainstream economics literature on diversified firms is extremely scant. The problem is, undoubtedly, that the standard neoclassical assumptions leave no role for these firms. Diversified firms are often referred to as 'conglomerates' and portrayed as inefficient results of 'empire building' by managers with unchecked agency problems. There is almost no literature on efficiency reasons for their existence.

Diversified firms fit much more comfortably in institutional economics where they appear as institutions for managing transactions costs. Accordingly, their nature and performance have attracted quite a lot of attention from institutional economists. This literature combines two observations that resonate strongly with the argument proposed here. First, Penrose (1959) suggested that firms grow to utilize excess capacity of managerial expertise (here 'factor capital') that cannot be sold because of transactions costs (here 'contracting costs'). Second, Richardson (1972) generalized this to other factors and introduced the idea that two activities (here 'businesses') are similar (here 'in the same neighborhood') when they draw on the same capabilities (here 'factor capital'). In the words of Foss and Langlois (1999), this implies that 'capabilities are the determinants of the boundary of the firm'. ${ }^{9}$ A similar point is developed in the management area by Argyres and Zenger (2012) who argue that the capabilities and transaction cost approaches to diversification cannot be separated. Our paper also combines the two but is based on excess capacity and business neighborhoods rather than complementarity.

The management literature on corporate diversification shares many influences with institutional economics, in particular Coase and Penrose, but has recently added a Ricardian flavor. ${ }^{10}$ The literature

\footnotetext{
${ }^{9}$ Foss and Langlois are two of the main drivers behind the revival of this stream. See e.g. Foss $(1993,1996)$ and Langlois (1998, 2004). Menard and Shirley (2014) is broader but also important.

${ }^{10}$ Wan et al. (2011) suggest that research on corporate diversification can benefit from combining insights from new institutional economics and management. Klein and Lien (2009) also straddle the two streams.
} 
started with Rumelt (1974) who defined 'core factors' as those that are indivisible and subject to transactions costs. He posited that we have 'economies of scope' and thus a basis for diversified firms, when individual markets are of limited size relative to the capacity of a core factor. ${ }^{11}$ This theory has been tested by, among others, Silverman (1999) who draws on Williamson (1975) to operationalize transactions costs. In the later, more Ricardo-inspired literature, the typical argument starts by asking what a focal firm can do better than other firms. It then focuses on the factors responsible and labels them 'resources' (Barney, 1991; Wernerfelt, 1984), 'competencies' (Prahalad and Hamel, 1990), 'capabilities' (Grant, 1996; Kogut and Zander, 1992), or 'dynamic capabilities' (Teece et al., 1997). It is posited that resources are 'hard to trade' since competitors otherwise could buy them and ultimately eliminate the rents. The literature, which often is referred to as the 'resource-based view of the firm' (RBV), argues that a firm's resources determine how it should compete in individual markets (in which it will earn Ricardian rents). The additional point, that resources in excess capacity should be leveraged in other industries where they are important, has been part of the RBV from the beginning (Wernerfelt, 1984). More recently, strategy scholars have looked at other factors of importance to diversification decisions, including the costs of changing scope, reductions in scope (de Figueiredo et al., 2019), and the costs of internal organization (Rawley, 2010). In the current paper, the cost of internal organization can be thought of as part of the cost of writing employment and ownership contracts. It is important to learn more about the origin and behavior of these costs but breaking them out in further detail would not change the conclusions reached here. It should finally be mentioned that the strategy literature on diversification resonates strongly with managers, who make the real-life diversification decisions about which it theorizes. ${ }^{12}$

In sum, the literatures in institutional economics and strategic management suggest that a firm should diversify from one industry into another if (1) it has excess capacity of factors that are indivisible, 'hard to trade', and yield Ricardian rents and (2) the second industry is 'related' to the first. Beyond adding a micro-foundation, we contribute to this literature in two ways. First, our factors do not have to be inherently indivisible. What matters is that contracting costs render them indivisible by making it economically unattractive to sell or rent fractions of them. Second, we make clear that industry relatedness should be defined in relation to a factor. A factor can support diversification into an industry if it creates value there and is more productive than any substitute available in the factor market.

As mentioned in the Introduction, the paper also makes a novel point about mechanisms that facilitate specialization. It has been known since Adam Smith (1965) and Stigler (1951) that markets enable specialization, and we add to this by introducing the diversified firm as another way of sustaining specialization and increasing the incentives to invest in it.

\subsection{Plan of the paper}

Since the model has many moving parts, we look at a simple small numbers version in section 2 and relegate the more complicated analysis of a large economy to Appendix A. The paper concludes with a brief discussion in section 3 .

\section{Small numbers model}

The model presented and analyzed here is as simple as possible while still containing the critical ingredients of the argument (which are underlined). The main cost of the simplicity, which matters less for a theory of diversified firms, is that the model does not portray 'firms' and 'markets' in a very intuitive way. These terms fit much more naturally in the large economy version analyzed in Appendix A.

\footnotetext{
${ }^{11}$ Similar arguments, also based on indivisibility and transactions costs, are developed by Teece (1980, 1982).

${ }^{12}$ As a rough gauge of the influence of this literature, the combined citation counts of the six above-mentioned papers exceed 240,000 (scholar.google.com, August 2021)
} 


\subsection{Economic environment}

This model has four businesses, $b_{1}, b_{2}, b_{3}$, and $b_{4}$, five factors, $f_{1}, f_{2}, f_{3}, f_{4}$, and $f_{5}$, four services, $s_{1}, s_{2}, s_{3}$, and $s_{4}$, and two periods. We initially imagine that the four businesses are owned by four different entrepreneurs and that the factors are owned by five different 'investors' or, in the case of human factors, by themselves. All players are risk-neutral, fully informed about the history of the game, and financially unconstrained. Each business 'needs' a specific service in each period and value is created if a factor performs that service for the business and only then. The needs are given in Table 1.

At the start of the first period, businesses advertise for factors. An ad specifies the factor capital a factor must have and whether the offered contract is for one period and one service, or for two periods and two services. ${ }^{13}$ Businesses may only contract with factors that have the specified factor capital and may only sign them to the advertised type of contract. Contracts are binding, but the parties can, if they both agree, terminate a two-period contract after the first period. If more than one factor meets the specifications of a business, the business hires one of them at price zero and the other goes unemployed also at zero pay.

Once they have seen the first period advertisements, investors endow their factors with factor capital (at a very small cost) and apply for contracts with the owner of $f_{1}$ acting first, the owner of $f_{2}$ acting second, etc. Each of them may choose to make their factor a specialist in one or none of $\left(s_{1}, s_{2}, s_{3}, s_{4}\right)$ and one or none of $\left(b_{1}, b_{2}, b_{3}, b_{4}\right)$. That is, factors can be specialized in a service and/or a business. (We can think of the pre-endowment factors as uneducated humans and cash.) Specialization works much like you would expect in the sense that the amount of value a factor creates depends on the fit between its factor capital and the (service, business) pair it works on. Specifically, the value it creates in each period is the sum of a service component and a business component. If it is specialized in a service (business) and performs (works for) that, the service (business) component is $v_{S}>1\left(v_{B}>1\right)$, while it is 1 if it is not specialized in any service (business). Finally, if a factor performs one service (or works for one business) but is specialized in another, that value component is normally 0 . (More on this below.) The weight on second period payoffs will be $\delta<1$, which also, since it varies with the period length, is a measure of the frequency with which needs change. To eliminate artifacts of the two-period format, we rule out behaviors in which investors choose their factor capital with no regard for the second period. This can be accomplished by assuming that the difference in efficiency between specialization and non-specialization, $\operatorname{Max}\left\{v_{S}-1, v_{B}-1\right\}$, is less than $\delta$.

Businesses that did not sign two-period contracts also advertise for factors in the second period. Factor capital can no longer change at that point, but available factors can again select a business to apply to.

It is an important feature of the model that some businesses are more similar than others. We capture this by dividing them into pairs or 'neighborhoods' characterized by two properties. First, the businesses in each neighborhood have correlated needs in the sense that a 'common service' in every period is needed by one of the neighbors. In this example, the neighborhoods are $\left(b_{1}, b_{2}\right)$ and $\left(b_{3}, b_{4}\right)$ and their common services are $s_{1}$ and $s_{3}$, respectively. Secondly, factor capital partially transfers between neighboring businesses such that a factor that is specialized in one, but works for the neighbor, still creates value $v_{B}{ }^{*} \in\left(0, v_{B}\right){ }^{14}$

A contract stipulates a single per-service price such that the services in two-period contracts are priced identically. (The function of this assumption is to rule out complete contracts.) The only nonstandard assumption in the model is that players incur sub-additive contracting costs. We do not specify a micro-foundation for these costs, but they could have to do with literal contracting costs (Dye, 1984), incomplete information bargaining (Bajari and Tadelis, 2001), the possibility of taking out ill will by perfunctory performance (Hart and Moore, 2008), rent seeking (Wernerfelt, 2015, 2016), or

\footnotetext{
${ }^{13}$ In the larger economy analyzed in Appendix A, second period needs are not known ex ante and two-period contracts give the business the right to specify a second period service from a very large set (give an order).

${ }^{14}$ Montgomery and Wernerfelt (1988) and Wernerfelt and Montgomery (1988) present evidence that average performance decreases with increasing diversification - a pattern consistent with $v_{B}^{*}<v_{B}$.
} 
Table 1. Needs per business and period

\begin{tabular}{lcc}
\hline Business & Need in first period & Need in second period \\
\hline$b_{1}$ & $s_{1}$ & $s_{4}$ \\
\hline$b_{2}$ & $s_{2}$ & $s_{1}$ \\
\hline$b_{3}$ & $s_{3}$ & $s_{2}$ \\
\hline$b_{4}$ & $s_{4}$ & $s_{3}$ \\
\hline
\end{tabular}

simply the unpleasantness and time cost of contracting. Depending on whether the contract covers one or two services, contracting costs are $K(1)$ and $K(2)$, respectively, and $K(1)<K(2)<2 K(1) .{ }^{15}$

While the sub-additivity may seem like a strong requirement, it is not unreasonable: For example, most people prefer not to bargain, but if they must, would rather bargain once over one $\$ 300$ pie than 30 times over $\$ 10$ pies. ${ }^{16}$ The same property seems natural for other contracting costs, such as those associated with writing, time, and hassle. To keep things simple, we assume that the players' bargaining power, and thus the division of value created minus contracting costs, is the same in all contracts.

Summarizing, the sequence of events is as follows:

(0) The needs of all firms in periods, as depicted in Table 1, are revealed to all players.

(1) Businesses post ads specifying the capital a factor must have, the number of periods for which it would be signed, and the service(s) it would have to perform.

(2) In order from $f_{1}$ to $f_{5}$, investors choose their factor capital profiles and select a business to apply to.

(3) Investors and businesses contract.

(4) Factors perform first period services and payoffs are made.

(5) Investor - business pairs that signed two-period contracts may agree to void them.

(6) Businesses that do not have a factor under contract for the second period post ads for that period, specifying the capital a factor must have and the desired service.

(7) In the order of their numbers, factors who are not signed for the second period select a business to apply to.

(8) Investors and businesses contract.

(9) Factors perform second period services, and payoffs are made.

\subsection{Results}

Depending on parameter values, the most efficient symmetric sub-game perfect equilibrium is one of five. In the 'ownership/employment' or 'firm' equilibrium, factors specialize in a business but not in a service. The contract runs for two periods and the factor performs a different service in each period with no further bargaining. The 'sequential contracting' equilibrium is very similar except for the fact that the parties negotiate two one-period contracts. So the difference between these depends on the sign of $K(2)-K(1)(1+\delta)$ and the firm can only be more efficient if $K()$ is sub-additive. In particular, sequential contracting is more efficient when needs change less frequently. ${ }^{17}$ In the 'market' equilibrium, factors specialize in services but not in businesses. They then start each period by contracting with the business that needs the service in question. Compared to a firm and sequential contracting,

\footnotetext{
${ }^{15}$ The model presents $K(2)$ as a one-time cost of organizing the firm, but it could be thought of as including all costs of internal organization.

${ }^{16}$ Consistent with this, Maciejovsky and Wernerfelt (2011) report on a laboratory experiment in which bargaining costs are found to be positive and sub-additive.

${ }^{17} \mathrm{~A}$ good example is large earth moving equipment. Construction companies often weigh whether to buy or rent such assets.
} 
the market is more attractive when the differences between services are greater than those between businesses in the sense that service-specialization is more efficient. ${ }^{18}$

Another class of equilibria created by the neighborhood structure will be called 'local market' equilibria. In these, two factors doubly specialize in a common service and the business that first needs it. They then switch to the neighboring business in the second period, thus taking advantage of both the correlation in needs and the partial transfer of factor capital. The other two factors can either specialize in a service and behave like market factors or specialize in a business and sign two one-period contracts.

LEMMA 1: When each entrepreneur operates exactly one business, the most efficient symmetric subgame perfect equilibrium is one of the following:

- In the market equilibrium, $f_{i}$ specializes in $s_{i}(i=1,2,3,4)$, and in each period negotiates a contract for that service with the business that needs it. Each factor and each business shares payoffs $\left(v_{S}+1\right)(1+\delta)-K(1)(1+\delta){ }^{19}$ The last factor, $f_{5}$, does not acquire factor capital and stays unemployed in this and all other equilibria.

- In the sequential contracting equilibrium, $f_{i}$ specializes in $b_{i}(i=1,2,3,4)$, and negotiates a oneservice contract with her in each period. Each factor, business pair shares payoffs $\left(1+v_{B}\right)(1+\delta)$ $-K(1)(1+\delta)$.

- In the firm equilibrium, $f_{i}$ also specializes in $b_{i}(i=1,2,3,4)$ but now negotiates a two-period contract with her. There is no new contracting in the second period. Each factor, business pair shares payoffs $\left(1+v_{B}\right)(1+\delta)-K(2)$.

- In two local market equilibria, $f_{1}\left(f_{2}\right)$ specializes in $s_{1}, b_{1},\left(s_{3}, b_{3}\right)$ and contracts with $b_{1}\left(b_{3}\right)$ in the first period and $b_{2}\left(b_{4}\right)$ in the second. These factors get a share of payoffs $v_{S}+v_{B}+\left(v_{S}+v_{B}^{*}\right) \delta-K(1)$ $(1+\delta)$. In the local market with market factors, $f_{3}\left(f_{4}\right)$ specializes in $s_{2}\left(s_{4}\right)$ and in each period contracts with the businesses that need this service, getting a share of payoffs $\left(v_{S}+1\right)(1+\delta)-K$ $(1)(1+\delta)$. In the local market with contractors, $f_{3}\left(f_{4}\right)$ will specialize in $b_{2}\left(b_{4}\right)$ and in the first period contract with her. However, since this business is 'taken' by $f_{1}\left(f_{2}\right)$ in the second period, $f_{3}\left(f_{4}\right)$ will sign a second period contract with $b_{1}\left(b_{3}\right)$, getting a share of payoffs $1+v_{B}+\delta\left(1+v_{B}^{*}\right)-K(1)(1+\delta)$.

\section{Proof: See Appendix B}

If entrepreneurs are allowed to own both businesses in a neighborhood, ${ }^{20}$ a new class of 'diversified firm' equilibria appear. In all of these, one entrepreneur owns $b_{1}$ and $b_{2}\left(b_{3}\right.$ and $\left.b_{4}\right)$, while $f_{1}\left(f_{2}\right)$ doubly specializes in $s_{1}, b_{1}\left(s_{3}, b_{3}\right)$ and contracts with the owner of the $b_{1}+b_{2}\left(b_{3}+b_{4}\right)$ businesses. The contract is for $s_{1}\left(s_{3}\right)$ but says that the owner can tell $f_{1}\left(f_{2}\right)$ which business to work for in the second period. (So the 'firm' label again comes from the fact that the factor obeys an order with no new contracting.)

Compared to the local market equilibria, the merged businesses have two advantages. First, the doubly specialized factors, $f_{1}$ and $f_{2}$, can sign a single two-period firm contract while still being able to work for both businesses in their neighborhoods. As a result, their contracting costs will be $K(1)$ which obviously is lower than the $(1+\delta) K(1)$ they had to pay in the local market equilibria. This means that local markets no longer can be efficient once diversified firms are allowed. Second, the other factors, $f_{3}$ and $f_{4}$, can also sign a two-period contract under which the owner of the neighborhood can tell them both which service to perform and which business to work for. They will have contracting costs $K(2)$ and their net payoff is identical to what they would have in the market, except that the latter have contracting costs $(1+\delta) K(1)$. Of course, $f_{3}$ and $f_{4}$ can also still be contractors or market factors, just like in the local markets.

\footnotetext{
${ }^{18}$ All this is known from Wernerfelt (2015).

${ }^{19}$ In a larger economy, like that analyzed in Appendix A, there should not be any contracting costs in the market.

${ }^{20}$ It should be clear that it is better to combine neighbors than two unrelated businesses.
} 
LEMMA 2: When each entrepreneur may operate either one or two businesses, the most efficient symmetric sub-game perfect equilibrium is either (single-business) firms, sequential contracting, the market, or one of three diversified firm equilibria.

- In all three diversified firm equilibria, $f_{1}\left(f_{2}\right)$ specializes in $s_{1}, b_{1},\left(s_{3}, b_{3}\right)$ and signs a firm contract with the owner of the $b_{1}+b_{2}\left(b_{3}+b_{4}\right)$ neighborhood. The contract gives the owner the right to tell the factors which business to work for but only specifies a single service. These factors get a share of payoffs $v_{S}+v_{B}+\left(v_{S}+v_{B}^{*}\right) \delta-K(1)$. In the diversified firm with a market factor, $f_{3}\left(f_{4}\right)$ specializes in $s_{2}\left(s_{4}\right)$ and signs two one-period contracts with two different diversified firms both covering this service. This gives two-period net value creation $(1+\delta)\left(v_{S}+1\right)-K$ $(1)(1+\delta)$. In the diversified firm with a contractor, $f_{3}\left(f_{4}\right)$ specializes in $b_{2}\left(b_{4}\right)$ and signs two one-period contracts with the owner of the $b_{1}+b_{2}\left(b_{3}+b_{4}\right)$ neighborhood. Since $f_{1}\left(f_{2}\right)$ will serve $b_{2}\left(b_{4}\right)$ in the second period, $f_{3}\left(f_{4}\right)$ will switch to $b_{1}\left(b_{3}\right)$. This gives two-period net value creation $1+v_{B}+\delta\left(1+v_{B}^{*}\right)-K(1)(1+\delta)$. Finally, in the diversified firm with an owned factor/an employee, $f_{3}\left(f_{4}\right)$ specializes in $b_{2}\left(b_{4}\right)$ and signs a two-period contract with the owner of the $b_{1}+b_{2}\left(b_{3}+b_{4}\right)$ neighborhood. Since $f_{1}\left(f_{2}\right)$ will serve $b_{2}\left(b_{4}\right)$ in the second period, $f_{3}\left(f_{4}\right)$ will switch to $b_{1}\left(b_{3}\right)$. This gives two-period net value creation $1+v_{B}+\delta\left(1+v_{B}{ }^{*}\right)-K(2)$.

Proof: See Appendix B

Noting that average per-factor net payoffs in the three diversified firm equilibria are $v_{S}+v_{B} / 2+1 / 2+$ $\left(v_{S}+v_{B}{ }^{*} / 2+1 / 2\right) \delta-K(1)(1+\delta / 2), v_{S} / 2+1 / 2+v_{B}+\left(v_{S} / 2+1 / 2+v_{B}^{*}\right) \delta-K(1)(1+\delta / 2)$, and $v_{S} / 2+1 / 2+$ $v_{B}+\left(v_{S} / 2+1 / 2+v_{B}^{*}\right) \delta-(K(1)+K(2)) / 2$, we now have, after some algebra:

PROPOSITION 1: In the most efficient symmetric sub-game perfect equilibria, any co-owned businesses will be neighbors. Furthermore, two businesses will be co-owned if $\operatorname{Max}\left\{\left(v_{S}-v_{B}\right)(1+\delta), 0, k(1)\right.$ $(1+\delta)-k(2)\} \leqslant v_{S} / 2-1 / 2+\left(v_{S} / 2-1 / 2+v_{B}^{*}-v_{B}\right) \delta+k(1) \delta / 2+\operatorname{Max}\left\{\left(v_{S}-v_{B}\right) / 2+\left(v_{S}-v_{B}{ }^{*}\right) \delta / 2,0,[k(1)\right.$ $(1+\delta)-k(2)] / 2\}$.

So the choice within each ownership category depends on $v_{S}-v_{B}, v_{S}-v_{B}^{*}$, and $k(1)(1+\delta)-k(2)$, while the choice between ownership categories to a large extent depends on how $v_{B}-v_{B}{ }^{*}$ compare with $v_{S}-1$. Specifically, the diversified firm is more efficient if $v_{S}-1$ is larger and $v_{B}-v_{B}{ }^{*}$ is smaller. This is consistent with the fact that diversified firms, compared to single-business firms, allows the parties to take advantage of more service-specialization at the cost of some decay in the gains from business-specialization. Note also that more frequent change, reflected in a higher $\delta$, favors equilibria with more firm contracts.

It also turns out that diversified firms cannot exist unless both assumptions made about neighborhoods hold.

COROLLARY 1: If neighboring businesses do not have correlated needs, diversified firms create less value than sequential contracting. If too little factor capital transfers between neighbors, diversified firms create less value than markets. ${ }^{21}$

\section{Proof: See Appendix B.}

We finally derive an appealing result about the optimal management of diversified firms. To this end, we assume that each service $\left(s_{1}, s_{2}, s_{3}, s_{4}\right)$ consumes some costless materials in proportion (normalized to 1$)$ to the value created. The materials-to-value ratios for $s_{1}$ and $s_{4}$ in $b_{1}$ are $\left[v_{S}+v_{B}\right] /\left[v_{S}+v_{B}+\left(v_{S}+\right.\right.$

\footnotetext{
${ }^{21}$ If an entrepreneur makes a mistake and announces factor demand for a less than maximally efficient equilibrium, factors have to follow whether they realize this or not. If they do not, they end up on the long side of a mechanism.
} 
1) $\delta]$ and $\left(v_{S}+1\right) \delta /\left[v_{S}+v_{B}+\left(v_{S}+1\right) \delta\right]$, respectively. In $b_{2}$, the ratios for $s_{2}$ and $s_{1}$ are $1 /(1+\delta)$ and $\delta /$ $(1+\delta)$, respectively. If the two businesses are merged, the ' $b_{2}$ division' will have materials-to-value ratios for $s_{2}$ and $s_{1}$ equal to $\left[v_{S}+1\right] /\left[v_{S}+1+\left(v_{S}+v_{B}{ }^{*}\right) \delta\right]$ and $\left[\left(v_{S}+v_{B}{ }^{*}\right) \delta\right] /\left[v_{S}+1+\left(v_{S}+v_{B}{ }^{*}\right) \delta\right]$, respectively. We can again perform similar calculations for the two other types of diversified firms. For both cases, simple algebra gives:

COROLLARY 2: Prior to the merger, the business with the doubly specialized factor has a higher materials-to-value ratio for the common service and a lower ratio for other services. The merger causes the ratios for the other business (which uses the doubly specialized factor in period 2) to change to resemble more closely those of the former business.

This result is consistent with the finding of Atalay et al. (2014) who report that newly acquired firms change their product-market mixes to resemble more closely those of their acquirers.

\section{Discussion}

We have proposed a micro-founded theory of diversified firms as mechanisms through which firms can leverage excess capacity of factors of production that are hard to trade in fractions. They expand into industries where these factors are needed and are more productive than versions that can be accessed in factor markets. This activity enables specialization beyond what can be achieved through the size of the market into which the original business is selling.

While diversified firms dominate modern economies, essentially all mainstream economic reasoning is based on single-business firms. The theory presented here suggests that there are important linkages between seemingly quite different industries, not because one supplies physical inputs to the other, but because they use common, often intangible, factors of production. These linkages have implications for efficiency and behavior. Furthermore, the theory suggests that the arrival of new multi- or single-use technologies may create or destroy inter-industry relationships and affect the demand for different types of specialized or standardized factors.

The theory is simple, intuitive, and based on benefits from specialization and sub-additive contracting costs. The role afforded to contracting costs is non-standard, and there may be a sense that such 'small' costs cannot explain large effects. However, the point is that these costs would be incurred with very high frequency in the absence of firms, thus giving them significant aggregate weight. A complementary point is that since firms are common, any explanation for their existence should be based on common forces.

As part of exploring the rationale for, and properties of, diversified firms, the paper contributes two results of additional interest: It shows that these firms manage their constituent businesses in similar ways and that they, like markets, enable specialization.

The results are lent additional credence by being broadly consistent with the prevailing logic in the management literature on corporate strategy. The paper is, more generally, part of a growing and potentially fruitful convergence between that literature and branches of economics interested in firms.

\section{References}

Argyres, N. S. and T. R. Zenger (2012), 'Capabilities, Transactions Costs, and Firm Boundaries', Organization Science, 23: $1643-1657$.

Atalay, E., A. Hortacsu and C. Syverson (2014), 'Vertical Integration and Input Flows', American Economic Review, 104: $1120-1148$.

Bajari, P. and S. Tadelis (2001), 'Incentives Versus Transaction Costs: A Theory of Procurement Contracts', Rand Journal of Economics, 32: 387-407.

Barnard, C. I. (1938), The Functions of the Executive, Cambridge, MA: Harvard University Press.

Barney, J. B. (1991), 'Firm Resources and Sustained Competitive Advantage', Journal of Management, 17: 99-120. 
Carter, R. and G. M. Hodgson (2006), 'The Impact of Empirical Tests of Transactions Cost Economics on the Debate on the Nature of the Firm', Strategic Management Journal, 27: 461-476.

Coase, R. H. (1937), 'The Nature of the Firm', Economica n. s, 4: 386-405.

de Figueiredo, R., E. Feldman and E. Rawley (2019), 'The Costs of Refocusing: Evidence from Hedge Fund Closures During the Financial Crisis', Strategic Management Journal, 40: 1258-1290.

Deakin, S., D. Gindis and G. M. Hodgson (2021), 'What is a Firm? A Reply to Jean-Philippe Robe', Journal of Institutional Economics, 17: 865-875.

Dye, R. A. (1984), 'Costly Contract Contingencies', International Economic Review, 26: 233-250.

Foss, N. J. (1993), 'Theories of the Firm: Contractual and Competence Perspectives', Journal of Evolutionary Economics, 3: $127-144$.

Foss, N. J. (1996), 'Knowledge-Based Approaches to the Theory of the Firm: Some Critical Comments', Organization Science, 7: 470-476.

Foss, N. J. and R. Langlois (1999), 'Capabilities and Governance: The Rebirth of Production in the Theory of Economic Organization', Kyklos, 52: 201-218.

Gindis, D. (2016), 'Legal Personhood and the Firm: Avoiding Anthropomorphism and Equivocation', Journal of Institutional Economics, 12: 499-513.

Grant, R. M. (1996), 'Towards a Knowledge-Based Theory of the Firm', Strategic Management Journal, 17: $109-122$.

Grossman, S. and O. D. Hart (1986), 'The Costs and Benefits of Ownership', Journal of Political Economy, 94: 691-719.

Hart, O. D. and J. Moore (2008), 'Contracts as Reference Points', Quarterly Journal of Economics, 123: 1-48.

Hodgson, G. M. (2019), 'Taxonomic Definitions in Social Science, with Firms, Markets, and Institutions as Case Studies', Journal of Institutional Economics, 15: 207-233.

Klein, P. G. and L. B. Lien (2009), 'Diversification, Industry Structure, and Firm Strategy: An Organizational Economics Perspective', Advances in Strategic Management, 26: 289-312.

Kogut, B. and U. Zander (1992), 'Knowledge of the Firm, Combinative Capabilities, and the Replication of Technology', Organization Science, 3: 383-397.

Langlois, R. (1995), 'Capabilities and Coherence in Firms and Markets', in C. A. Montgomery (ed.), Resource-Based and Evolutionary Theories of the Firm: Towards a Synthesis, Boston: Kluwer: 71-100.

Langlois, R. (1998), 'Capabilities and the Theory of the Firm', in N. J. Foss and B. J. Loasby (eds), Economic Organization, Capabilities, and Co-ordination: Essays in Honor of G. B. Richardson, London, UK: Routledge, pp. 183-203.

Langlois, R. (2004), 'Chandler in a Larger Frame: Markets, Transactions Cost, and Organizational Form in History', Enterprise and Society, 5: 355-375.

Maciejovsky, B. and B. Wernerfelt (2011), 'Costs of Implementation: Bargaining Costs versus Allocative Efficiency', Journal of Economic Behavior and Organization, 77: 318-325.

Matouschek, N. (2004), 'Ex Post Inefficiencies in a Property Rights Theory of the Firm', Journal of Law, Economics, and Organization, 20: 125-147.

Menard, C. and M. M. Shirley (2014), 'The Future of New Institutional Economics: From Early Intuitions to a New Paradigm?', Journal of Institutional Economics, 10: 541-565.

Montgomery, C. A. and B. Wernerfelt (1988), 'Diversification, Ricardian Rents, and Tobin's q', RAND Journal of Economics, 19: 623-632.

Montgomery, C. A. and B. Wernerfelt (1992), 'Risk Reduction and Umbrella Branding', Journal of Business, 65: 31-50.

Novak, S. and B. Wernerfelt (2012), 'On the Grouping of Actions into Firms: Make-or-Buy with Interdependent Parts', Journal of Economics and Management Strategy, 21: 53-77.

Penrose, E. (1959), The Theory of the Growth of the Firm, New York, NY: John Wiley and Sons.

Prahalad, C. K. and G. Hamel (1990), 'The Core Competence of the Corporation', Harvard Business Review, 68: 79-91.

Rawley, E. (2010), 'Diversification, Coordination Costs, and Organizational Rigidity: Evidence from Microdata', Strategic Management Journal, 31: 873-891.

Richardson, G. B. (1972), 'The Organization of Industry', Economic Journal, 82: 883-896.

Rumelt, R. P. (1974), Strategy, Structure, and Economic Performance, Boston, MA: Division of Research, Harvard Business School.

Silverman, B. S. (1999), 'Technological Resources and the Direction of Corporate Diversification: Toward an Integration of the Resource-Based View and Transactions Cost Economics', Management Science, 45: 1109-1124.

Simon, H. A. (1951), 'A Formal Theory of the Employment Relationship', Econometrica, 19: 293-305.

Smith, A. (1965), The Wealth of Nations, New York, NY: Modern Library, (First Edition, 1776).

Stigler, G. J. (1951), 'The Division of Labor is Limited by the Extent of the Market', Journal of Political Economy, 59: 185-193.

Teece, D. J. (1980), 'Economies of Scope and the Scope of the Enterprise', Journal of Economic Behavior and Organization, 1: 223-247.

Teece, D. J. (1982), 'Towards an Economic Theory of the Multiproduct Firm', Journal of Economic Behavior and Organization, 3: 39-63. 
Teece, D. J., G. Pisano and A. Shuen (1997), 'Dynamic Capabilities and Strategic Management', Strategic Management Journal, 18: 509-533.

Wan, W. P., R. E. Hoskisson, J. C. Short and D. W. You (2011), 'Resource-Based Theory and Corporate Diversification: Accomplishments and Opportunities', Journal of Management, 37: 1335-1368.

Wernerfelt, B. (1984), 'A Resource-Based View of the Firm', Strategic Management Journal, 5: 171-180.

Wernerfelt, B. (1997), 'On the Nature and Scope of the Firm: An Adjustment-Cost Theory', Journal of Business, 70: 489-514.

Wernerfelt, B. (2015), 'The Comparative Advantages of Firms, Markets, and Contracts: A Unified Theory', Economica, 82: 350-367.

Wernerfelt, B. (2016), 'All Adaptations are not the Same: The Scope of Firms and the Size of Markets', Chapter 5 in B. Wernerfelt (ed.), Adaptation, Specialization, and the Theory of the Firm: Foundations of the Resource-Based View, Cambridge, UK: Cambridge University Press.

Wernerfelt, B. and C. A. Montgomery (1988), 'Tobin's $q$ and the Importance of Focus in Firm Performance', American Economic Review, 78: 246-250.

Wernerfelt, B., A. Silk and S. Yu (2021), 'On the Internalization of Advertising and Marketing Services: An Adaptation Cost Analysis', Marketing Science: forthcoming.

Williamson, O. E. (1975), Markets and Hierarchies: Analysis and Antitrust Implications, New York, NY: The Free Press.

\section{APPENDIX A}

\section{Diversified firms in a large economy}

This model is in some ways a scaled version of that in section 2, but the scale allows us to endow firms and markets with more natural properties, consider a wider range of factor capital, and reduce the role of contracting costs. We continue to use the notation from section 2 but need to expand it a bit.

\section{Model}

The basic economic environment is the same as that analyzed in section 2. Businesses, operated by entrepreneurs, produce by using factors, initially owned by investors, to perform services. Each business $b \in \boldsymbol{B}$ needs one service, $s_{b}^{t} \in \boldsymbol{A}$, in each period $t$, and if a needed service $s$ is performed by the factor $f$, it creates $v_{s b f}$ units of value. Any factor can perform any service at zero cost, but only one per period and value cannot be created by using two factors or by performing an unneeded service. We here assume that the number of services $S$ is greater than the number of factors $F$, and that the latter is greater than the number of businesses $B .^{22}$ The model covers two time periods, $t=1,2$, and $\delta \in(0,1)$ is the weight on second period payoffs. All players are risk-neutral, financially unconstrained, and at all times perfectly informed about the entire history of the game.

Businesses come in pairs called neighborhoods and $N(b)$ denotes the neighborhood of which $b$ is a member. The businesses in $N(b)$ need the common service $s_{b}^{*}$ in one period each and two different services in the other periods. ${ }^{23}$

Given the above, we can describe the first and second period distributions of needs. In the first period, each business has a $50 \%$ chance of needing the common service associated with its neighborhood and an equal chance of needing any of the other $S-1$ services. The second period distribution depends on the first period realizations in two ways. First, a business that did not need its neighborhood's common service in period 1 will need it in period 2 . Second, to keep the analysis uncluttered, we assume that the total number of businesses needing each service is the same in both periods. Beyond these constraints, second period needs are random draws.

Very early in the game, investors endow their factors with factor capital (at a very small cost). We can think of the pre-endowment factors as uneducated humans and cash, but the post-endowment, they can be specialized in a service and/or a business. In the service domain, the factor may be specialized in an individual service or services in general. Similarly, in the business domain, they may be specialized in an individual business or businesses in general. Because no misunderstanding should be possible, we use the subset of $\boldsymbol{S} \times \boldsymbol{B}$ in which a factor is specialized as shorthand for its factor capital profile. So $f$ s factor capital is summarized in its profile $\left(h_{f S}, h_{f B}\right) \in\left\{\{s\}_{s \in \boldsymbol{S}}, \boldsymbol{S}\right\} \times\left\{\{b\}_{b \in \boldsymbol{B}}, \boldsymbol{B}\right\}$.

The production function is additive. When $f$ performs $s$ for $b$, the value created per period is $v_{s b f}=v_{s f}+v_{b f}$ where $v_{s f}$ depends on $h_{f S}$ and the match between it and $s$, while $v_{b f}$ depends on $h_{f B}$ the match between it and $b$. Both business and service components are 1 if the factor has general capital, they are $v_{S}>1$ and $v_{B}>1$, respectively, if it has specialized capital

\footnotetext{
${ }^{22}$ We think of $S$ as very large including many end products as well as alternative ways of making them.

${ }^{23}$ This is obviously very strong assumption. It rules out three interesting cases; that in which one business sometimes needs the common service in both periods, that in which the members of a neighborhood sometimes do not need the common service, and that in which both of them sometimes need it in the same period. The first of these adds little, but the second allows us to explain why employment relationships occasionally break down, and the third could be used to introduce waiting time as an additional cost of in-house specialists. Unfortunately, all generalizations complicate the formulas and give rise to several new 'cases'. So rather than obscuring the main message of the present paper, we leave them to future research.
} 
and works in the exact service or business. The productivities are 0 if it works beyond the neighborhood or the service in which it is specialized. Reflecting the idea that neighboring businesses are 'similar', the business component of value creation is $v_{B}{ }^{*} \in\left(0, v_{B}\right)$ if the factor is specialized to one business and works for its neighbor. These productivities mean that business neighborhoods are defined by two properties: Needs are correlated, and factor capital is partially transferable from individual businesses to their neighbors.

Once they know their needs for a period, businesses advertise for factors. A posting from business $b$ specifies the desired factor capital $\left(h_{b S}, h_{b B}\right)$ and the number of periods ( 1 or 2$)$ for which the factor would be signed. This again determines how the price will be arrived at. If $h_{b B}=b$, the price will be found through bilateral contracting and if $h_{b B}=\boldsymbol{B}$, it will be found in a market with other businesses and other factors. We make six assumptions about the contracting mechanisms.

- Any mechanism produces agreement on exactly one price.

- All mechanisms which have the same number of participants (factors and businesses) on each side, will produce the same division of net payoffs. ${ }^{24}$ In all other cases, the long side gets negative payoffs. Factors who do not participate in any mechanism stay unemployed and get zero payoff. (Factors who anticipated being unemployed will not even undertake the small cost of acquiring factor capital.)

- Contracts are binding, but the parties can agree to terminate a two-period contract after the first period.

- Businesses are committed to the specification in their factor postings. They can only hire factors with the advertised factor capital and only for the advertised number of periods.

- In mechanisms involving more than one entrepreneur, the parties incur no contracting costs and are matched with randomly chosen trading partners. ${ }^{25}$

- In mechanisms involving a single entrepreneur, the parties incur contracting costs totaling $K(\sigma)$, where $\sigma$ is the number of services covered by the contract, $K(0)=0$, and $K()$ is sub-additive in the sense that $K(\sigma)<\sigma K(1)$.

So in a two-period model, firms can only exist if $K(S) \leqslant(1+\delta) K(1)$, which again requires that $K()$ be sub-additive.

To avoid a possible artifact of the two-period setting, we assume that the second period is so important that no factor will want to specialize in a single service (other than common service) or a single business to do well in the first period while hoping to avoid a change in the second period. This requires that the extra payoff from specialization cannot be too big relative to the weight on the second period. Specifically, we need that $\delta>\operatorname{Max}\left\{v_{S}-1, v_{B}-1\right\}$.

The sequence of events is as follows.

First period needs are known ex ante.

Businesses post ads specifying a factor capital and the number of periods (one or two) for which it would be signed. In the order of their numbers, the owners of factors choose their factor capital profiles and select a business to apply to. Mechanisms are executed.

First period services are performed, and payoffs are made.

Second period needs are realized.

Business-factor pairs that signed two-period contracts may agree to void them.

Businesses that are not bound by two-period contracts post ads for the second period, specifying the factor capital desired.

Businesses that are bound by two-period contracts tell their factors which services to perform in the second period.

In the order of their numbers, factors that are not bound by two-period contracts select a business to apply to.

Mechanisms are executed.

Second period services are performed, and payoffs are made.

We will be looking for the most efficient symmetric sub-game perfect equilibria.

\section{Analysis}

We start by focusing on single-business firms. Except for the fact that contracting costs are zero in markets, this analysis mirrors that in section 2. When businesses are very different in the sense that the value of business-specific factor capital is high, the most efficient equilibria are those in which factors stay with the same business in both periods and thus invest in business-specific factor capital. The use of firms depends on the frequency with which adaptations are needed. If changes are frequent, a firm is best, and otherwise sequential contracting. ${ }^{26}$ When services are very different, the most efficient subgame perfect equilibrium is that in which market factors stay with the same service in both periods and invest in the corresponding factor capital. The existence of business neighborhoods creates a fourth option in which factors do two different things. In these equilibria, the first factor to enter a neighborhood will specialize in the common service and the business

\footnotetext{
${ }^{24}$ The 'net' refers to the contracting costs introduced below.

${ }^{25}$ The random matching means that players cannot avoid contracting costs by entering a market and then trading with their preferred partner.

${ }^{26}$ This is tested in Novak and Wernerfelt (2012).
} 
that needs it in period 1. Factors who are later in the queue are in a less attractive position and will use either sequential contracting, the market solution, or not invest at all (on the expectation that they will be unable to find a job). Formally, we have

LEMMA 3: When each entrepreneur operates exactly one business, the most efficient symmetric sub-game perfect equilibrium is one of the following:

Firm: $\left(h_{f S}, h_{f B}\right)=(S, b)$ and a two-period contract covering $S$. This gives two-period net value creation $\left(1+v_{B}\right)(1+\delta)-K$ $(s)$. In this and all other equilibria, factors with indices above $B$ will acquire no factor capital and remain unemployed.

Sequential contracting: $\left(h_{f S}, h_{f B}\right)=(S, b)$, and two one-period contracts with the same business covering $s^{1}{ }_{b}$ and $s^{2}{ }_{b}$. Two-period net value creation is $\left(1+v_{B}\right)(1+\delta)-(1+\delta) K(1)$.

Global market: $\left(h_{f S}, h_{f B}\right)=(s, \boldsymbol{B})$ and two one-period contracts with two different businesses both covering $s$. Two-period net value creation is $\left(v_{S}+1\right)(1+\delta)$.

Local market with a contractor: Label two neighboring businesses such that $s^{1}{ }_{b}=s^{*}{ }_{b}$ and $N(b)=\left\{b, b^{\prime}\right\}$. One of the first $B / 2$ factors sets $\left(h_{f S}, h_{f B}\right)=\left(s_{b}^{*}, b\right)$ and signs two one-period contracts first with $b$ and then $b$, both covering $s^{*}$. Its two-period net value creation is $v_{S}+v_{B}+\delta\left(v_{S}+v_{B}^{*}\right)-(1+\delta) K(1)$. One of the next $B / 2$ factors sets $\left(h_{f S}, h_{f B}\right)=\left(S, b^{\prime}\right)$ and signs two one-period contracts first with $b^{\prime}$ and then with $b$, covering $s^{1}{ }^{\prime}$ and $s^{2}{ }_{b}$. Its two-period net value creation is $1+v_{B}+\delta\left(1+v_{B}{ }^{*}\right)-(1+\delta) K(1)$.

Local market with a market factor: One of the first $B / 2$ factors again sets $\left(h_{f S}, h_{f B}\right)=\left(s^{*} b, b\right)$ and signs two one-period contracts first with $b$ and then $b$, both covering $s_{b}^{*}$. Its two-period net value creation is $v_{S}+v_{B}+\delta\left(v_{\mathrm{S}}+v_{B}{ }^{*}\right)-(1+\delta) K(1)$. One of the next $B / 2$ factors sets $\left(h_{f S}, h_{f B}\right)=(s, \boldsymbol{B})$ and signs two one-period contracts with two different businesses both covering a. This gives it two-period net value creation $\left(v_{S}+1\right)(1+\delta)$.

Since the proof is very similar to that of lemma 1 , it is omitted.

We next look at the case in which each entrepreneur operates two businesses. Since it is obvious that the most efficient such firms consist of neighboring businesses, we focus on that case. To facilitate comparison with the single-business case, we express productivity on a two-period per-factor basis.

When each entrepreneur operates a pair of neighboring businesses, three new sub-game perfect equilibria appear. Two of them are similar to, but dominate, the local markets. In both of these, one factor again chooses to doubly specialize, but now only negotiates once (with the owner of both the neighboring businesses). So these equilibria dominate both local market equilibria. The new equilibrium is similar, but the factor who is not doubly specialized is now owned by/an employee of, the combined business. The contract gives the owner the right to tell it which service to perform and which business to work for. An analog solution was not possible in the local market context because the two businesses were not co-owned.

If we label two neighboring businesses such that $s^{1}{ }_{b}=s^{*}{ }_{b}$ and $N(b)=\{b, b\}$, the formal characterizations of the two-business equilibria are:

LEMMA 4: When each entrepreneur may operate either one or two businesses, the most efficient symmetric sub-game perfect equilibrium is either a (single-business) firm, sequential contracting, the market, or one of three equilibria in which $B / 2$ factors are owned by/employees of, diversified firms, while another $B / 2$ are either market factors, contractors, or owned/ employees. The last $F-B$ factors are unemployed.

Diversified firm with a market factor: One of the first $B / 2$ factors sets $\left(h_{f S}, h_{f B}\right)=\left(s^{*}, b\right)$ and signs a two-period contract with the owner of the neighborhood covering $s_{b}^{*}$. Its two-period net value creation is $v_{S}+v_{B}+\delta\left(v_{S}+v_{B}^{*}\right)-K(1)$. One of the next $B / 2$ factors sets $\left(h_{f S}, h_{f B}\right)=(s, B)$ and signs two one-period contracts with two different businesses both covering $s$. This gives two-period net value creation $(1+\delta)\left(v_{S}+1\right)$.

Diversified firm with a contractor: Label two neighboring businesses such that $s^{1}{ }_{b}=s^{*}{ }_{b}$ and $N(b)=\{b$, b' $\}$. One of the first $B / 2$ factors sets $\left(h_{f S}, h_{f B}\right)=\left(s_{b}^{*}, b\right)$ and signs a two-period contract with the owner of the neighborhood covering $s^{*}$. Its twoperiod net value creation is $v_{S}+v_{B}+\delta\left(v_{S}+v_{B}^{*}\right)-K(1)$. One of the next $B / 2$ factors sets $\left(h_{f S}, h_{f B}\right)=\left(S, b^{\prime}\right)$ and signs two oneperiod contracts first with $b^{\prime}$ and then with $b$, covering $s^{1}{ }_{b}$ and $s^{2}{ }_{b}$. Its two-period net value creation is $1+v_{B}+\delta\left(1+v_{B}{ }^{*}\right)-(1$ $+\delta) K(1)$.

Diversified firm with an owned factor/an employee: Label two neighboring businesses such that $s^{1}{ }_{b}=s^{*}{ }_{b}$ and $N(b)=\left\{b, b^{\prime}\right\}$. One of the first $B / 2$ factors sets $\left(h_{f S}, h_{f B}\right)=\left(s^{*} b, b\right)$ and signs a two-period contract with the owner of the neighborhood covering $s_{b}^{*}$. Its two-period net value creation is $v_{S}+v_{B}+\delta\left(v_{S}+v_{B}{ }^{*}\right)-K(1)$. One of the next $B / 2$ factors sets $\left(h_{f S}, h_{f B}\right)=\left(S, b^{\prime}\right)$ and signs a two-period contract with the owner of the neighborhood, covering $s^{1}{ }_{b}$ and $s^{2}{ }_{b}$. His two-period net value creation is $1+v_{B}+\delta\left(1+v_{B}^{*}\right)-K(\boldsymbol{S})$.

Since the proof is very similar to that of lemma 2 , it is omitted.

We can easily evaluate the efficiency of the multi-business equilibria by comparing the average per-factor payoffs to those in the single-business equilibria. Noting that average per-factor net payoffs in the three diversified firm equilibria are $v_{S}+v_{B} / 2+$ $1 / 2+\left(v_{S}+v_{B}^{*} / 2+1 / 2\right) \delta-K(1) / 2, v_{S} / 2+1 / 2+v_{B}+\left(v_{S} / 2+1 / 2+v_{B}^{*}\right) \delta-K(1)(1+\delta / 2)$, and $v_{S} / 2+1 / 2+v_{B}+\left(v_{S} / 2+1 / 2+v_{B}^{*}\right) \delta$ $-(K(1)+K(S)) / 2$, we have, after some algebra: 
PROPOSITION 2: In the most efficient symmetric sub-game perfect equilibria, any jointly operated businesses will be neighbors. Furthermore, entrepreneurs will operate a diversified firm in equilibrium if ${ }^{27} \operatorname{Max}\left\{\left[v_{S}-v_{B}+k(1)\right](1+\delta), 0, k\right.$ $(1)(1+\delta)-k(\mathrm{~S})\} \leqslant v_{S} / 2-1 / 2+\left(v_{S} / 2-1 / 2+v_{B}^{*}-v_{B}\right) \delta+k(1) \delta / 2+\operatorname{Max}\left\{\left[\left(v_{S}-v_{B}\right)+\left(v_{S}-v_{B}^{*}\right) \delta+k(1)(1+\delta]\right) / 2,0,[k(1)(1+\delta)\right.$ $-k(S)] / 2\}$

The proposition also allows us to see that diversified firms are dominated by single-business firms or sequential contracting if neighboring businesses do not have correlated needs and by the global market if too little factor capital transfers inside business neighborhoods (such that $v_{B}^{*}<1$ ).

COROLLARY 3: If neighboring businesses do not have correlated needs, diversified firms create less value than sequential contracting. If too little factor capital transfers between neighbors, diversified firms create less value than markets.

Since the proof is very similar to that of corollary 1 , it is omitted.

\section{APPENDIX B}

\section{Proof of lemma 1}

Since factors get no payoffs if they do not get a job, $f_{1}, f_{2}, f_{3}$, and $f_{4}$ will select the factor capital required for, and take, the best job on offer when it is their time to choose in the first period and take the best job on offer if and when they have to choose in the second period. The last factor, $f_{5}$, has no incentives to incur the small factor capital cost on the equilibrium path. However, if one of the factors selecting earlier invests in the 'wrong' factor capital, $f_{5}$ will take that factor's place. So we can focus on the businesses, start in the second period, and work backwards.

If a business has to post a job ad in the second period, it will only ask for factor capital that is represented in the pool of factors available to it - a pool that is determined by the first period contracts. In principle, first period contracts can be any one of eight types: They can cover one or two periods and factors can specialize in a service, a business, both of those, or be unspecialized. We can, however, eliminate four of alternatives: It clearly does not make sense to hire an unspecialized factor for any length of time or to sign a two-period contract with a factor that is specialized in a service. Furthermore, signing a doubly specialized factor for two periods would get a business a share of $v_{S}+v_{B}+v_{B} \delta-K(2)$, whereas a similar contract with a business specialized factor gives it a share of $\left(1+v_{B}\right)(1+\delta)-K(2)$, which, since $\delta>v_{S}-1$, is bigger. (Since bargaining power is the same across all contracts, we will hence forth operate with the total value created by a business or a factor and drop the 'share of prefix.) So we are down to four possible first-period contracts: service specialization with one-period contracts, business specialization with one- or two-period contracts, and double specialization with one-period contracts. If $f_{1}$ $\left(f_{2}\right)$ specializes in $s_{1}, b_{1},\left(s_{3}, \mathrm{~b}_{3}\right)$ when $v_{B}^{*}<1, f_{5}$ will specialize in $s_{1}\left(s_{3}\right)$ and since this is more efficient, all parties will agree that it should replace the errant factor in the second period. Given this, $f_{1}\left(f_{2}\right)$ will only double specialize when $v_{B}^{*} \geqslant 1$.

We will now go through all possible factor pools at the start of the second period when first period equilibria are symmetric. Suppose that there are four service specialists on the second period factor market. In this case, the businesses will advertise for factors that are specialized in the service they need in the second period. So if they, in the first period, advertise one period contracts for factors that are specialized in the service they need in that period, their two-period payoff will be $\left(v_{S}+1\right)(1+\delta)-K(1)(1+\delta)$. Similarly, if there are four business specialists on the second period factor market, contracts in both periods will specify business specialization and have one period duration, giving the businesses two-period payoff $\left(1+v_{B}\right)(1+\delta)-K(1)(1+\delta)$. Finally, if there are no factors available, all businesses initially signed two-period contracts with business specialists and will get two-period payoff $\left(1+v_{B}\right)(1+\delta)-K(2)$.

If there are two service specialists and two business specialists or just two of one of these, two of the businesses can do better by switching to the strategy employed by the others. So this cannot happen in any equilibrium. If there are four double specialists, the businesses cannot get dual specialization benefits in both periods but have to do with $v_{S}+0$ or $0+v_{B}$ in one of the periods, presumably the second. But since $\delta>\operatorname{Max}\left\{v_{S}-1, v_{B}-1\right\}$, this will give them total payoffs below either $\left(v_{S}+1\right)(1+\delta)-(1+\delta) K(1)$ or $\left(1+v_{B}\right)(1+\delta)-(1+\delta) K(1)$. So this cannot be efficient. Finally, if there are two double specialists, the businesses that are looking for second period factors cannot do better than renewing the contract with their first period factors, giving them at most $v_{S}+v_{B}+\delta v_{B}-(1+\delta) K(1)<\left(1+v_{B}\right)(1+\delta)-(1+\delta) K(1)$. So also this cannot be efficient.

Suppose next that there are two double specialists and two service specialists and that the double specialists worked for $b_{1}$ and $b_{3}$ in the first period. In this case, $b_{1}$ and $b_{3}$ will want to be served by service specialists in the second period (preferring $v_{S}+1$ over $0+v_{B}$ ) while $b_{2}$ and $b_{4}$ will ask for the double specialists, getting $v_{S}+v_{B}{ }^{*}$. (As discussed above, this only happens if $v_{B}^{*}>1$.) The average business payoff in this equilibrium is $v_{S}+1 / 2+v_{B} / 2+\delta\left(v_{S}+1 / 2+v_{B}^{*} / 2\right)-(1+\delta) K(1)$. This is more efficient than anything that can be achieved if the double specialists worked for $b_{2}$ and $b_{4}$ in the first period.

\footnotetext{
${ }^{27}$ This is different from the condition in Proposition 1 because we here have no contracting costs in the market.
} 
Consider finally the case in which the second period factor market consists of two double specialists and two business specialists and assume that the double specialists worked for $b_{1}$ and $b_{3}$ in the first period. In this case, $b_{1}$ and $b_{3}$ will want to be served by business specialists in the second period (preferring $1+v_{B^{*}}$ over $0+v_{B}$ ) while $b_{2}$ and $b_{4}$ will ask for the double specialists (getting $\left.v_{S}+v_{B}^{*}\right)$. The average business payoff in this equilibrium is $v_{S} / 2+1 / 2+v_{B}+\delta\left(v_{S} / 2+1 / 2+\right.$ $\left.v_{B}^{*}\right)-(1+\delta) K(1)$. Also this is more efficient than anything that can be achieved if the double specialists worked for $b_{2}$ and $b_{4}$ in the first period.

So depending on $\max \left\{\left(v_{S}+1\right)(1+\delta)-K(1)(1+\delta),\left(1+v_{B}\right)(1+\delta)-(1+\delta) K(1),\left(1+v_{B}\right)(1+\delta)-K(2), v_{S}+1 / 2+v_{B} / 2+\delta\right.$ $\left.\left(v_{S}+1 / 2+v_{B}^{*} / 2\right)-(1+\delta) K(1), v_{S} / 2+1 / 2+v_{B}+\delta\left(v_{S} / 2+1 / 2+v_{B}^{*}\right)-(1+\delta) K(1)\right\}$, the most efficient symmetric sub-game perfect equilibrium is either the global market, sequential contracting, a firm, the local market with a market factor, or the local market with a contractor, and the latter two equilibria further require that $v_{B}^{*}>1$.

It remains to be shown that none of the five regions described above are empty. We will just show this with numerical examples. The global market is best if $v_{S}=2, v_{B}=1, \delta=1, K(2)=2 K(1)$, and $v_{B}^{*}=0$. Sequential contracting is best if $v_{S}=1$, $v_{B}=2, \delta=1, K(2)=2 K(1)$, and $v_{B}^{*}=0$. The firm is best if $v_{S}=1, v_{B}=2, \delta=1, K(2)=K(1)$, and $v_{B}^{*}=0$. The local market with a market factor is best if $v_{S}=2, v_{B}=1, \delta=1, K(2)=2 K(1)$, and $v_{B}^{*}=2$. The local market with a contractor is best if $v_{S}=3 / 2$, $v_{B}=2, \delta=1, K(2)=2 K(1)$, and $v_{B}^{*}=2$.

\section{Proof of lemma 2}

This is very similar to the local market equilibrium with two exceptions. First, if $b_{1}$ and $b_{2}$ merge, $f_{1}$ can doubly specialize in $s_{1}, b_{1}$ and write just one contract (with the owner of the merged business) in which he agrees to perform $s_{1}$ for either $b_{1}$ or $b_{2}$. Since the parties thus avoid the second period contracting costs, the expected value created by any business or factor is $\delta K(1)$ larger than in the corresponding local market. Second, $f_{3}$ can now also write an ownership/employment contract (with the owner of the merged business) in which he agrees to perform either $s_{2}$ or $s_{4}$ for either $b_{1}$ or $b_{2}$. Contrary to what is the case in the local market with a contractor, this contract does not prevent it, or its doubly specialized peer, from shifting from one business to the other. Since this carry contracting costs $K(\boldsymbol{S})$, versus $(1+\delta) K(1)$ in the otherwise identical diversified firm with a contractor, either equilibrium may be more efficient than the other.

\section{Proof of corollary 1}

Without the correlated needs, doubly specialized factors in diversified firms make $v_{S}+v_{B}+\delta v_{B}^{*}-K(1)(1+\delta)$. This is less than the payoff from sequential contracting $\left(1+v_{B}\right)(1+\delta)-K(1)(1+\delta)$ since $\operatorname{Max}\left\{v_{S}-1, v_{B}-1\right\}<\delta$. If too little factor capital transfers between neighbors in the sense that $v_{B}{ }^{*}<1$, the second period payoff with doubly specialized factors in diversified firms, $\delta\left(v_{S}+v_{B}^{*}\right)$, is less than the $\delta\left(v_{S}+1\right)$ that would be achieved with $f_{5}$. Since this therefore will be more efficient and $f_{5}$ 's alternative is to make 0 , the diversified firm can pay the originally hired factor to dissolve the contract. Knowing this, $f_{1}\left(f_{2}\right)$ will not doubly specialize unless $v_{B}^{*}>1$.

Cite this article: Wernerfelt B (2022). Diversified firms: existence and behaviors. Journal of Institutional Economics 18, 345-360. https://doi.org/10.1017/S1744137421000709 